\title{
TINJAUAN KRITIS PENERAPAN PERENCANAAN PARTISIPATIF PADA PROYEK JKEGIATAN IDENTIFIKASI PENGEMBANGAN POTENSI DAERAH IRIGASI LENGGI KABUPATEN PATI
}

\author{
Rizqy Ridho Prakasa ${ }^{1}$,Marzuqotul IImiyah² \\ ${ }^{1}$ Program Studi Perencanaan Wilayah dan Kota, Universitas Semarang; Email: rizqyridho21@gmail.com; \\ 2Program Studi Perencanaan Wilayah dan Kota, Universitas Semarang; Email: marzuqotulilmiyah85304@gmail.com;
}

Info Artikel:

- Artikel Masuk: 03/03/21

- Artikel diterima: 20/03/21

- Tersedia Online: 30/03/21

\begin{abstract}
ABSTRAK
Pengembangan potensi daerah irigasi merupakan suatu bagian tindak lanjut terhadap adanya suatu potensi yang terdapat di daerah irigasi. Pengembangan potensi bertujuan memanfaatkan sumber daya alam yang ada di sekeliling masyarakat menggunakan teknologi yang relevan dengan kebutuhan, serta adanya peningkatan kesejahteraan petani serta mengurangi kesenjangan antar wilayah. Identifikasi pengembangan potensi Daerah Irigasi Kabupaten Pati yang mengembangkan potensi Daerah Irigasi Lenggi sebagai aspek lain yang dapat dikembangkan lebih lanjut sehingga dapat berguna untuk menambah perekonomian petani atau masyarakat sekitar. Pembahasan ini disusun dengan melihat dari sudut pandang praktikan dalam suatu instansi dengan membandingkan antara kondisi di lapangan dengan teori terkait. Praktikan melihat dari sudut pandang substansi dalam Identifikasi pengembangan potensi Daerah Irigasi Kabupaten Pati. Substansi yang akan dijelaskan yakni mengenai konsep Perencanaan Partisipatif, yang nantinya diterapkan pada penyusunan rencana pengembangan potensi pada Daerah Irigasi Lenggi dalam Identifikasi Pengembangan Potensi Daerah Irigasi Lenggi..
\end{abstract}

Kata Kunci : Identifikasi Pengembangan Potensi Daerah Irigasi Lenggi; Perencanaan Partisipatif; Tinjauan Kritis

\section{ABSTRACT}

The development of the potential of an irrigation area is a part of the follow-up to the potential that exists in an irrigation area. The development of the potential aims to utilize natural resources around the community by using technology that is relevant for needs and improving the welfare of farmers and reducing disparities between regions. Identification of the potential development of the Pati Regency Irrigation Area which develops the potential of the Lenggi Irrigation Area as another aspect that can be further developed so that it can be useful to increase the economy of farmers or the surrounding community. This discussion is prepared by looking from point of view the practitioner in an institution by comparing the conditions in the field with related theories. Praktikan see from the point of view of the substance the identification of potential development of the Irrigation Area in Pati Regency. The substance to be explained is the concept of Participatory Planning, which will be applied to the preparation of potential development plans for the Lenggi Irrigation Area in the Identification of Lenggi Irrigation Area Potential Development.

Keyword: Identification of Potential Development of Lenggi Irrigation Area; Participatory Planning; Critical Review

\section{PENDAHULUAN}

Perencanaan partisipatif didefinisikan sebagai perencanaan yang menekankan terkait peran serta aktif dari masyarakat dalam perencanaan pembangunan mulai dari pengenalan wilayah, pengidentifikasian masalah sampai penentuan skala prioritas. Dalam UU No. 25 Tahun 2004 menjelaskan "partisipasi masyarakat" yakni keikutsertaan masyarakat dalam mengakomodasi kepentingan mereka dalam proses penyusunan rencana pembangunan.

Kegiatan pembangunan diawali dengan proses perencanaan, maka dari itu dengan sendirinya juga diperlukan suatu metode pendekatan perencanaan partisipatif. Metode yang dimaksud mensyaratkan masyarakat untuk diikutsertakan dalam proses perencanaan. Perencanaan yang dilakukan menggunakan metode tersebut dapat sebagai dasar pada kajian kepada masalah yang mereka hadapi serta potensi yang tersedia di dalam masyarakat.

Metode Perencanaan partisipatif merupakan sebuah metode pendekatan untuk memberikan kesempatan masyarakat untuk terlibat secara langsung dalam proses pengambilan keputusan terkait urusan-urusan 
publik, sehingga keputusan yang diambil memiliki dasar informasi yang tidak memiliki kesalahan dan dapat diterima oleh masyarakat.

Betapa pentingnya peran masyarakat dalam mengambil keputusan dikhususkan dalam konteks keputusan yang bersifat kepentingan publik. Kondisi sekarang metode partisipasi masyarakat dalam penyelenggaraan pemerintahan, perencanaan, dan pembuatan kebijakan sudah dilegalkan dalam perundang undangan.

Bentuk implementasi perencanaan partisipatif yang dilakukan di Indonesia yakni Kegiatan Musrenbang (Musyawarah Perencanaan Pembangunan) yang dilakukan di daerah - daerah.

Kegagalan pada program - program pembangunan pedesaan di masa lalu disebabkan antara lain karena penyusunan, pelaksanaan dan evaluasi program-program tersebut tidak dilibatkannya masyarakat setempat. Pembangunan yang terjadi dilakukan dengan tidak aspiratif dan parsipatif yang membuat hasil perencanaan dan dalam proses pembangunan terutama di tingkat desa menjadi tidak berkelanjutan. Daerah Irigasi Lenggi terletak di wilayah utara Kabupaten Pati tepatnya pada kecamatan Dukuhseti yang mempunyai luas areal baku $521 \mathrm{Ha}$. Area persawahan yang luas menyuguhkan suasana asri perdesaan yang menjadi potensi pengembangan kawasan tersebut.

Pengembangan daerah irigasi sedang gencar - gencarnya dilakukan pemerintah pusat dalam program kegiatan IPDMIP atau sering dsiebut Integrated Participatory Development and Management Irrigation Project bertujuan untuk mewujudkan kedaulatan pangan nasional yang mengedepankan kemajuan sektor pertanian, serta meningkatkan kesejahteraan petani Indonesia. Kegiatan ini berbasis partisipasi masyarakat, maka peran serta masyarakat petani sangat dibutuhkan dalam kegiatan ini. Dalam kegiatan tersebut, petani merupakan salah satu dari tiga unsur dalam Program IPDMIP, yaitu ketersediaan benih, ketersediaan air, dan ketersediaan sumberdaya manusia (petani). Oleh sebab itu, melalui kegiatan tersebut diharapkan mampu menciptakan partisipasi aktif petani khususnya di daerah irigasi sehingga produktivitas hasil pertanian dapat meningkat.
Persawahan yang luas menjadi potensi yang ada di Daerah Irigasi Lenggi dan juga menjadi rencana yang akan dikembangkan. Pada kondisi yang ada, potensi tersebut hanya menghasilkan output hasil pertanian padi yaitu beras. Padahal jika dikembangkan lagi, pertanian padi yang luas tersebut dapat menghasilkan output lebih banyak lagi. Kegiatan perencanaan dan pengembangan membutuhkan peran serta masyarakat dapat memperjuangkan kepentingan dan masyarakat sejahtera sesuai kondisi obyektif yang ada.

Rencana pengembangan wilayah yang berbasis perencanaan partisipatif akan menjadi utama dalam pelaksanaan pengembangan Daerah Irigasi Lenggi, sehingga memaksimalkan pengembangan potensi sesuai dengan kondisi yang ada dapat dinikmati dalam dimensi yang nyata. Mewujudkan rencana pengembangan yang telah disebutkan maka diperlukan peran serta masyarakat sekitar dalam mengidentifikasi potensi dan permasalahan Daerah irigasi Lenggi Kecamatan Dukuhseti Kabupaten Pati.

Dari penjelasan diatas, maka muncul pertanyaan "Bagaimana implementasi perencanaan partisipatif pada pekerjaan proyek Identifikasi Pengembangan Potensi Daerah Irigasi Lenggi Kecamatan Dukuhseti Kabupaten Pati 2020?"

Jawaban dari pertanyaan diatas akan menjadi pembahasan dalam laporan ini. Jawaban tersebut juga menjadi tujuan bagi praktikan untuk mengetahui bentuk implementasi perencanaan partisipatif pada pekerjaan proyek Identifikasi Pengembangan Potensi Daerah Irigasi Lenggi Kecamatan Dukuhseti Kabupaten Pati 2020 melalui telaah dokumen dari kajian literatur.

\section{DATA AND METODE}

Metode pelaksanaan penelitian adalah sebagai berikut:

1. Pengarahan dan tanya jawab, berupa penjelasan dari pembimbing bidang Infrastruktur Kewilayahan/ Lapangan (Tenaga Pendamping Masyarakat) serta pejabat instansi tentang mekanisme kerja

2. Observasi, melaksanakan pengamatan tentang pelaksanaan pekerjaan proyek yaitu 
pengamatan daerah irigasi, saluran irigasi maupun bendung irigasi.

3. Wawancara dan atau FGD, dilakukan melalui percakapan dan diskusi yang melibatkan masyarakat petani dengan maksud mendapatkan data sekunder seperti kondisi lapangan Daerah Irigasi, permasalahan dan kebutuhan masyarakat petani serta aspirasi masyarakat petani. Sedangkan yang menjadi sasarannya yaitu GP3A (Gabungan Petani Pemakai Air), P3A (Petani Pemakai Air), ketua maupun anggota Kelompok Tani Daerah Irigasi Lenggi.

4. Penggunaan Dokumen, merupakan suatu laporan serta dokumen yang ada hubungannya dengan kajian teknis dari pengembangan potensi Daerah Irigasi Lenggi yang dijadikan subjek pengamatan.

5. Studi Literatur, didapatkan dari literatur, buku dan telaah dokumen yang berhubungan dengan pengembangan potensi Daerah Irigasi.

Dalam metode pengumpulan data mempergunakan dalam pekerjaan proyek adalah data primer dan data sekunder.

1. Data Primer, diperoleh dari wawancara, observasi dan FGD. Data primer yang dikumpulkan dalam pekerjaan proyek tersebut meliputi potensidan permasalahan yang ada di lapangan.

2. Data Sekunder, pengumpulan data sekunder dilakukan dengan studi literatur baik pustaka tulis maupun elektronik (internet). Literatur yang digunakan berisi informasi tentang halhal yang berkaitan dengan pekerjaan proyek yang dilakukan.

\section{HASIL DAN PEMBAHASAN}

Judul pekerjaan proyek yang diambil dalam penelitian ini adalah Identifikasi Pengembangan Potensi Daerah Irigasi Lenggi Kecamatan Dukuhseti Kabupaten Pati tahun anggaran 2020.
Pekerjaan proyek tersebut termasuk dalam kegiatan Koordinasi Perencanaan Pengelolaan Sistem Irigasi Partisipatif (PPSIP) yang merupakan pengelolaan infrastruktur irigasi secara metode perencanaan partisipatif pada jaringan irigasi tersier, secara teknis dilaksanakan oleh Perkumpulan Petani Pemakai Air (P3A) dimana pembinaan terhadap kelembagaan petani tersebut menjadi wewenang dan tanggung jawab dari instansi pemerintah yang menangani pertanian.

Ruang lingkup stubstansial pada pekerjaan proyek tersebut mencakup kegiatan:

1. Mengidentifikasi data sekunder untuk menemukan dan mengenali potensi dan permasalahan pengembangan Daerah Irigasi Lenggi

2. Mengidentifikasi data primer di lapangan

3. Melaksanakan kegiatan berdasarkan dengan pendekatan partisipatif melalui wawancara dan atau FGDMenganalisis potensi dan permasalahan Daerah Irigasi

4. Menyusun rekomendasi dan indikasi rencana kegiatan

Sesuai dengan tujuan laporan penelitian yaitu mengetahui implementasi pekerjaan proyek berbasis perencanaan partisipatif dengan teoriteori yang berkaitan dengan perencanaan partisipatif melalui telaah dokumen dari kajian literatur, maka berikut adalah tabel pembahasan penerapan substansi konsep dan langkah langkah perencanaan patisipatif. 
Tabel 1.

Pembahasan Penerapan Substansi Konsep Perencanaan Partisipatif Proyek Kegiatan Identifikasi Pengembangan Potensi Daerah Irigasi Lenggi

\begin{tabular}{|c|c|c|c|c|c|}
\hline No & Variabel & $\begin{array}{c}\text { Keterangan Kajian } \\
\text { Literatur }\end{array}$ & $\begin{array}{c}\text { Penerapan Konsep } \\
\text { Perencanaan Partisipatif } \\
\text { Proyek Kegiatan Identifikasi } \\
\text { Pengembangan Potensi } \\
\text { Daerah } \\
\text { Irigasi Lenggi }\end{array}$ & Perbandingan & $\begin{array}{c}\text { Rencana } \\
\text { Tindak Lanjut }\end{array}$ \\
\hline 1. & $\begin{array}{l}\text { Berorienta } \\
\text { si kepada } \\
\text { masyaraka } \\
\text { t }\end{array}$ & $\begin{array}{l}\text { Perencanaan } \\
\text { berdasarkan } \\
\text { permasalahan } \\
\text { permasalahan yang ada dan } \\
\text { kebutuhan masyarakat, } \\
\text { memperhatikan aspirasi } \\
\text { masyarakat dengan sikap } \\
\text { terbuka dan saling percaya }\end{array}$ & $\begin{array}{l}\text { Pekerjaan proyek didasarkan } \\
\text { pada } \\
\text { 1. Permasalahan petani } \\
\text { Daerah Irigasi Lenggi yaitu } \\
\text { belum optimalnya saluran } \\
\text { irigasi serta belum } \\
\text { optimalnya pengelolaan } \\
\text { hasil pertanian. } \\
\text { 2. Kebutuhan petani DI Lenggi } \\
\text { dengan } \\
\text { memperhatikan aspirasi } \\
\text { masyarakat } \\
\text { normalisasi sungai lenggi, } \\
\text { kebutuhan } \\
\text { kelengkapan } \\
\text { pengembangan fasilitas } \\
\text { pertanian seperti sektor } \\
\text { pengairan, jalan yang } \\
\text { memadahi dan sarana- } \\
\text { sarana penunjang lainnya. }\end{array}$ & - & - \\
\hline 2. & $\begin{array}{l}\text { Keterlibatan } \\
\text { masyarakat }\end{array}$ & $\begin{array}{l}\text { Masyarakat didalam forum } \\
\text { pertemuan, memiliki } \\
\text { peluang yang sama dalam } \\
\text { sumbangan pemikiran tanpa } \\
\text { dihambat oleh kemampuan } \\
\text { bicara, waktu dan tempat }\end{array}$ & $\begin{array}{l}\text { Pada pekerjaan proyek } \\
\text { terdapat keterlibatan } \\
\text { masyarakat melalui wawancara } \\
\text { dan atau FGD yang dilakukan } 1 \\
\text { kali dalam sebulan } \\
\text { dimulai dari awal proyek } \\
\text { kegiatan sampai evaluasi }\end{array}$ & - & - \\
\hline
\end{tabular}


Indonesian Journal of Spatial Planning, Vol. 2, No. 1, tahun 2021, 36-44

\begin{tabular}{|c|c|c|c|c|c|}
\hline 3. & Dinamis & $\begin{array}{l}\text { Perencanaan merupakan } \\
\text { bentuk pencerminan } \\
\text { kepentingan dan kebutuhan } \\
\text { semua pihak dan proses } \\
\text { perencanaan berlangsung } \\
\text { secara berkelanjutan dan } \\
\text { proaktif }\end{array}$ & - & $\begin{array}{l}\text { Belum ada proses } \\
\text { perencanaan } \\
\text { berlangsung secara } \\
\text { berkelanjutan }\end{array}$ & $\begin{array}{l}\text { Menyusun } \\
\text { mekanisme tindak } \\
\text { lanjut rencana } \\
\text { pengembangan } \\
\text { potensi Daerah } \\
\text { Irigasi Lenggi } \\
\text { seperti } \\
\text { menyiapkansarana } \\
\text { dan prasarana, } \\
\text { mengembangkan } \\
\text { keterpaduan } \\
\text { jaringan dan } \\
\text { pengelolaan } \\
\text { prasarana dan } \\
\text { sarana yang terkait } \\
\text { dengan pan } \\
\text { pengembangan } \\
\text { ekonomi wilayah } \\
\text { yaitu hasil pertanian } \\
\text { Daerah Irigasi Lenggi }\end{array}$ \\
\hline 4. & Sinergitas & $\begin{array}{l}\text { Adanya jaminan akan } \\
\text { keterlibatan semua pihak, } \\
\text { setiap rencana yang akan } \\
\text { dibangun sedapat mungkin } \\
\text { menjadi kelengkapan yang } \\
\text { sudah ada maupun sedang } \\
\text { atau dibangun serta } \\
\text { memperhatikan interaksi } \\
\text { yang terjadi diantara } \\
\text { stakeholder }\end{array}$ & $\begin{array}{l}\begin{array}{l}\text { Pekerjaan proyek melibatkan } \\
\text { semua pihak } \\
\text { terutama }\end{array} \\
\text { stakeholder terkait meliputi } \\
\text { Ketua P3A (Petani Pemakai } \\
\text { Air) masing masing desa, } \\
\text { Ketua GP3A (Gabungan Petani } \\
\text { Pemakai Air), Poktan, } \\
\text { Gapoktan, Pemda melalui } \\
\text { dinas terkait dan lainnya. } \\
\text { Bentuk Sinergitas dari kegiatan } \\
\text { proyek tersebut meliputi } \\
\text { bersatunya semua pihak dari } \\
\text { masyarakat petani dalam } \\
\text { membantu pengenalan wilayah } \\
\text { sampai rencana } \\
\text { pengembangan }\end{array}$ & - & - \\
\hline
\end{tabular}


Indonesian Journal of Spatial Planning, Vol. 2, No. 1, tahun 2021, 36-44

\begin{tabular}{|c|c|c|c|c|c|}
\hline & & & $\begin{array}{l}\text { yang melalui persetujuan } \\
\text { masyarakat petani. }\end{array}$ & & \\
\hline 5. & Legalitas & $\begin{array}{l}\text { Perencanaan embangunan } \\
\text { dilaksanakan berpedomana } \\
\text { kepada semua peraturan } \\
\text { yang berlaku, menjunjung } \\
\text { etika dan tata nilai } \\
\text { masyrakat dan tidak } \\
\text { memberikan peluang bagi } \\
\text { penyalahgunaan wewenang } \\
\text { dan kekuasaan }\end{array}$ & - & $\begin{array}{l}\text { Belum ada peraturan } \\
\text { setempat yang berlaku } \\
\text { dalam pengembangan } \\
\text { potensi Daerah Irigasi }\end{array}$ & $\begin{array}{l}\text { Menyusun } \\
\text { pedoman, } \\
\text { pemberian } \\
\text { bimbingan, arahan } \\
\text { mengenai } \\
\text { kebijakan dan } \\
\text { rencana } \\
\text { pengembangan } \\
\text { wilayah termasuk } \\
\text { Wilayah pertanian } \\
\text { Daerah Irigasi } \\
\text { yang melibatkan } \\
\text { masyarakat. }\end{array}$ \\
\hline 6. & Realistis & $\begin{array}{l}\text { Perencanaan memiliki sifat } \\
\text { yakni spesifik, terukur, dapat } \\
\text { dijalankan, dan } \\
\text { mempertimbangkan waktu. }\end{array}$ & $\begin{array}{l}\text { Rencana pengembangan } \\
\text { potensi DI Lenggi bersifat } \\
\text { 1. Spesifik, yang artinya proyek } \\
\text { kegiatan tersebut ditujukan } \\
\text { langsung atau khusus pada } \\
\text { kelompok sasaran tertentu } \\
\text { seperti masyarakat petani agar } \\
\text { dapat menyejahterakan para } \\
\text { petani sekitar }\end{array}$ & - & - \\
\hline
\end{tabular}

Sumber: Analisis Penyusun, 2020 
Tabel 3.

Pembahasan Penerapan Langkah-Langkah Perencanaan Partisipatif Proyek Kegiatan Identifikasi Pengembangan Potensi Daerah Irigasi Lenggi

\begin{tabular}{|c|c|c|c|c|c|}
\hline No & Variabel & Keterangan Kajian Literatur & $\begin{array}{c}\text { Penerapan Konsep Perencanaan } \\
\text { Partisipatif Proyek Kegiatan Identifikasi } \\
\text { Pengembangan Potensi Daerah } \\
\text { Irigasi Lenggi }\end{array}$ & Perbandingan & $\begin{array}{l}\text { Rencana } \\
\text { Tindak } \\
\text { Lanjut }\end{array}$ \\
\hline 1. & Penyelidikan & $\begin{array}{l}\text { Proses ajakan kepada masyarakat } \\
\text { untuk mengenali secara seksama } \\
\text { problem yang mereka hadapi }\end{array}$ & $\begin{array}{l}\text { 1. Proses } \\
\text { melalui FGD }\end{array}$ & - & - \\
\hline 2. & $\begin{array}{l}\text { Perumusan } \\
\text { Masalah }\end{array}$ & $\begin{array}{l}\text { Masukan dari masyarakat yang } \\
\text { dihimpun benar- benar merupakan } \\
\text { apa yang dirasakan dan apa yang } \\
\text { menjadi keprihatinan dari } \\
\text { masyarakat }\end{array}$ & $\begin{array}{l}\text { Output dari FGD merupakan bahan masukan } \\
\text { data yang dihimpun untuk merumuskan masalah } \\
\text { yang dilakukan oleh Tenaga Pendamping } \\
\text { Masyarakat (TPM) }\end{array}$ & - & - \\
\hline 3. & $\begin{array}{l}\text { Identifikasi } \\
\text { Daya Dukung }\end{array}$ & $\begin{array}{l}\text { Daya dukung dapat tergantung } \\
\text { kepapada: } \\
\text { (1) persoalan yang ada, } \\
\text { (2) tujuan yang ingin dicapai } \\
\text { aktifitas yang akan dilakukan. }\end{array}$ & $\begin{array}{l}\text { Pengidentifikasian daya dukung merupakan } \\
\text { hasil FGD yang dilakukan oleh TPM maupun } \\
\text { pihak perencana yang ada di Bappeda } \\
\text { Kabupaten Pati }\end{array}$ & - & - \\
\hline 4. & $\begin{array}{l}\text { Perumusan } \\
\text { Tujuan }\end{array}$ & $\begin{array}{l}\text { Tujuan merupakan cerminan } \\
\text { kondisi yang diharapkan, rangkaian } \\
\text { langkah dimaksudkan untuk } \\
\text { kepentingan rakyat, maka mutlak } \\
\text { adanya keterlibatan } \\
\text { rakyat (dalam arti keterlibatan } \\
\text { secara sadar). }\end{array}$ & $\begin{array}{l}\text { Perumusan tujuan dilakukan oleh masyarakat, } \\
\text { stakeholder setempat dengan Tenaga } \\
\text { Pendamping Masyarakat dibantu oleh pihak } \\
\text { perencana yang ada di Bappeda Kabupaten } \\
\text { Pati }\end{array}$ & - & - \\
\hline 5. & $\begin{array}{l}\text { Langkah } \\
\text { Langkah Rinci }\end{array}$ & $\begin{array}{l}\text { Melakukan tahapan rumusan lebih } \\
\text { utuh, perencanaan dalam sebuah } \\
\text { rencana tindakan }\end{array}$ & $\begin{array}{l}\text { Penentuan langkah langkah rinci yaitu melakukan } \\
\text { perencanaan dalam sebuah rencana tindakan } \\
\text { yang dilakukan oleh Tenaga Pendamping } \\
\text { Masyarakat dibantu } \\
\text { oleh pihak perencana yang ada di Bappeda } \\
\text { Kabupaten Pati }\end{array}$ & - & - \\
\hline 6. & $\begin{array}{l}\text { Penyusunan } \\
\text { Rencana } \\
\text { Anggaran }\end{array}$ & $\begin{array}{l}\text { Melakukan penyusunan alokasi } \\
\text { anggaran atau sumber daya yang } \\
\text { tersedia }\end{array}$ & $\begin{array}{l}\text { Penyusunan rencana anggaran oleh pihak } \\
\text { perencana yang ada di Bappeda Kabupaten } \\
\text { Pati }\end{array}$ & - & - \\
\hline
\end{tabular}

Sumber: Analisis Penyusun, 2020 
Penerapan perencanaan partisipatif pada pekerjaan proyek sudah sesuai dengan teori langkah langkah perencanaan partisipatif yang ada. Keterlibatan masyarakat dalam pekerjaan proyek berbasis perencanaan partisipatif merupakan hal terpenting, karena dengan keterlibatan masyarakat dapat mengenali secara rinci tentang permasalahan yang dihadapi dan kebutuhan masyarakat sendiri. Selain itu, aspirasi masyarakat juga dapat membantu berjalannya pekerjaan proyek ini.

Penerapan substansi konsep perencanaan partisipatif, terdapat beberapa variabel yang belum diterapkan dipekerjaan proyek Identifikasi Pengembangan Potensi Daerah Irigasi Lenggi Kecamatan Dukuhseti Kabupaten Pati 2020. Perencanaan partisipatif yang diimplementasikan kepada proyek tersebut dalam kegiatan alur dari suatu perencanaan belum berlangsung secara berkelanjutan dan proaktif yang artinya pekerjaan proyek tersebut jika sudah dilaksanakan selanjutnya belum terdapat rencana yang berkelanjutan. Proyek tersebut dalam perencanaan partisipatifnya juga belum melaksanakan perencanaan pengembangan yang mengacu pada semua peraturan yang berlaku karena belum ada peraturan setempat yang berlaku dalam pengembangan potensi daerah irigasi

\section{KESIMPULAN}

Ponggok people realize that the water Penjelasan yang telah disebutkan baik dari penjelasan konsep perencanaan partisipatif maupun penerapan konsep perencanaan partisipatif di Daerah Irigasi Lenggi, dan tinjauan kritis terhadap konsep perencanaan partisipatif pada proyek kegiatan Identifikasi Pengembangan Potensi Daerah Irigasi Lenggi dapat diambil beberapa kesimpulan.

1. Penerapan pada konsep TOD belum dapat dijelaskan secara spesisfik tentang bagaimana proses perencanaan berlangsung secara berkelanjutan yang ditandai dengan belum tersusunnya mekanisme tindak lanjut rencana pengembangan potensi Daerah Irigasi Lenggi.
2. Belum ada peraturan setempat yang berlaku dalam pengembangan potensi Daerah Irigasi

\section{REFERENSI}

Abe, A. 2002. Perencanaan Daerah Partisipatif. Solo: Pondok Edukasi

Abady, A. P. (2013). Perencanaan partisipatif dalam pembangunan daerah. Otoritas: Jurnal Ilmu Pemerintahan, 3(1).

Akbar, I. (2018). Perencanaan Partisipatif

Dalam Pembangunan Lokal: Studi Di Kota Bandung. Jurnal Reformasi Administrasi: Jurnal IImiah untuk Mewujudkan Masyarakat Madani, 5(2), 101-108.

Fadil, F. (2013). Partisipasi masyarakat dalam musyawarah perencanaan pembangunan di Kelurahan Kotabaru Tengah. Jurnal Ilmu Politik dan Pemerintahan Lokal, 2(2), Juli- Desember 2013.

Fuldauer, L. I., Ives, M. C., Adshead, D., Thacker, S., \& Hall, J. W. (2019). Participatory planning of the future of waste management in small island developing states to deliver on the Sustainable Development Goals. Journal of cleaner production, 223, 147-162.

Kantemeridou, C., Tsantopoulos, G., Tampakis, S., \& Karanikola, P. (2013). Participatory planning and local economic development: a case study of Northeast Halkidiki. Procedia Technology, 8, 459464.

Mustanir, A., Hamid, H., \& Syarifuddin, R. N. (2019). Pemberdayaan Kelompok Masyarakat Desa Dalam Perencanaan Metode Partisipatif. MODERAT: Jurnal IImiah Ilmu Pemerintahan, 5(3), 227-239.

Nugroho, Riant : 2003, Reinventing Pembangunan, Gramedia, Jakarta.

Rachmawati, N., Siraj, N., \& Bharoto, R. H. (2018). Implementasi Perencanaan Partisipatif Dalam Pembangunan Fisik Di Desa Suci Kecamatan Mundu Kabupaten Cirebon. Jurnal Ilmiah Publika, 6(2).

Riyadi dan Bratakusumah, D. S, 2004. Perencanaan Pembangunan Daerah, PT.. Gramedia Pustaka Utama, Jakarta. 
Solihah, R. (2020). Perencanaan Partisipatif Dalam Program Citarum Harum Di Desa Kutamandiri Kecamatan Tanjungsari Kabupaten Sumedang. Kumawula: Jurnal Pengabdia Kepada

Masyarakat, 3(1), 29-47.

Thomas Oni Veriasa. 2016. Partipasi Masyarakat dalam Perencanaan Pembangunan Desa: Studi Kasus Perencanaan Pembangunan Desa di Desa Karang Tengah, Kecamatan Babakan Madang, Kabupaten Bogor. Papper. Institut Pertanian Bogor, 2016.

Tjokroamidjoyo, Bintoro,1996 Perencanaa Pembangunan,Gunung Agung, Jakarta 